\title{
"I'm walking on eggshells": Challenges faced by mothers with breast cancer in interacting with adolescent daughters
}

Pingting Zhu ( $\sim$ ptzhu@yzu.edu.cn )

Yangzhou University

Qiaoying Ji

Yangzhou University

Xinyi Liu

Yangzhou University

Ting Xu

Yangzhou University

Qiwei Wu

Yangzhou University

Yuejuan Wang

Yangzhou University

\section{Research Article}

Keywords: breast cancer, mothers, adolescent daughters, relationships, women's health

Posted Date: November 9th, 2021

DOI: https://doi.org/10.21203/rs.3.rs-1000506/v1

License: (c) (i) This work is licensed under a Creative Commons Attribution 4.0 International License.

Read Full License 


\section{Abstract \\ Background}

With breast cancer becoming the most diagnosed cancer in the world, the number of breast cancer mothers with adolescent children is also rising. And for adolescent daughters, their mother server as a primary figure among the key processes of identification with their gender, femininity and sexuality. But breast cancer threats mother's health including such a key symbol of her womanhood, the breast. Which may adversely affect the development of an adolescent daughter's own sense of personal identity and womanhood. However, few researchers and practitioners on mother-daughter interactions in the context of breast cancer, therefor this study is aimed to reveal the nuances of interactive challenges with adolescent daughters faced by mother with breast cancer from mother' perspective.

\section{Methods}

A qualitative study was conducted. With the sample saturation principle, data collected by semistructured interviews with 21 breast cancer patients who are in line with breast conserving. Colaizzi's method of phenomenology was used for data analysis and Foucauldian discourse approach was also partially integrated into the analysis for this research.

\section{Results}

Three major themes emerged from the data. The themes were the following: (1) Mothers are lost in chaos (unable to deal with the shock of cancer, powerlessness of the uncertainty about the life span, and confused about how to respond to daughter's curiosity); (2) Mothers struggle for balance (protect daughter or let her be independent, as a mother or a patient); and (3) Mothers are immersed in guilt (increasing risk of cancer for daughters, influencing the development of daughter, and bring burden to daughter).

\section{Conclusions}

Our findings explore the interaction experience of breast cancer mothers and adolescence daughters, and further reveal the nuances of mother-daughter interaction challenges faced by mother with breast cancer from mother' perspective. To help mothers enhance interaction with their daughters and assist health practitioners to translate our findings into health interventions.

\section{Background}

Breast cancer has become the most diagnosed cancer in the world.[1] In 2020, women aged 15 to 44 account for $33.5 \%$ of breast cancer cases, which means that a large number of women with breast cancer 
may have children younger than 18 years.[2] They are dependent on their mother in daily life may experience difficulties when dealing with the mother's diagnosis of and treatment for breast cancer.[3, 4] Given the volatility of the stages of adolescence, adolescents are at risk of being negatively impacted by their mothers' illnesses, especially adolescent daughters. $[5,6]$ This may be because daughters could become more involved with the household duties, independent, and sensitive to their mothers' illnessrelated stress.[7] It worth to note that breast cancer is different from other oncological diseases, it play a unique role in mother-daughter relationships. Mother's illness increased daughters' risk of breast cancer, [8] Chan found that more than one half of a sample of daughters of women with breast cancer reported elevated levels of worry about breast cancer, their mother's illness heightened their personal sense of vulnerability to the disease.[9] In addition, adolescent daughters are in the key processes of identification with their gender, femininity and sexuality.[10] But breast cancer threats their mother's health including such a key symbol of her womanhood, the breast. Which may have the potential to disrupt the confidence and understanding that the adolescent girl held for her own developing body.[11] And mothers serve as a primary socializing figure among adolescent daughters,[12] and their breast cancer has relevance to the development of an adolescent daughter's own sense of personal identity and womanhood.[13] Therefore, mothers with breast cancer face their adolescent daughter's distress and fear in addition to experiencing psychological and physical symptoms of breast cancer.[14]

However, researchers and practitioners tend to focus on marital interactions, and conversely, few studies on mother-daughter interactions in the context of breast cancer exists. This may be because the mother and daughter are intergenerational, it embodies unique challenges. Research to date, although scarce, suggests that diagnosed mothers and daughters report shared changes on many levels and emotional problems are intergenerational.[15] Higher daughter anxiety was associated with higher maternal anxiety and poorer family communication. Higher daughter breast cancer-specific distress was associated with higher maternal breast cancer-specific distress.[16, 17] These psychological effects can even extend further and result in physiological changes (e.g., impaired immunological functioning and increased stress hormones) for both mothers and their daughters.[18] However, existing literature on the nuances of challenges in the interactions between breast cancer mothers and their adolescent daughters is lacking. In our research, we sought to better understand the mother-daughter interaction challenges faced by mother with breast cancer from mother' perspective.

And it is important to explore the secrecy of the challenges and complicate interactions of mothers with breast cancer. A Foucauldian discourse approach,[19] such as was applied in our research, was integrated into the analysis for this research and utilized to examine discourses that revealed how complex and sometimes seemingly conflicted perspectives on mothers' lived experiences. The challenges faced by mothers with breast cancer in interacting with adolescent daughters brought to light through the identification of these themes and assist health practitioners in developing helpful interaction strategies for the interaction between mother and adolescent daughter.

\section{Methods}




\section{Participants}

We used purposeful sampling with maximum diversity to extract breast cancer mothers with adolescent daughter. The inclusion criteria for participants consisted of the followings: (1) Female patients; (2) The daughters were raised at the age of 13 to 18 years old; (3) With normal cognitive ability and language expression ability, no verbal communication barrier; (4) Informed of the purpose and content of this study and voluntary participation. The exclusion criteria were inability to complete the interview. Data collection continued until the repeated occurrence of information and no new themes emerged from the interviews. [20] Finally, 21 breast cancer mothers were interviewed. Participants' demographic characteristics were shown in Table 1.

Table 1

Sample Characteristics $(\mathrm{N}=21)$

\begin{tabular}{|ll|}
\hline Characteristic & Range \\
\hline Age(years) & $31-44(39.81 \pm 5.00)$ \\
\hline Diagnosis of breast cancer (months) & $2-23(8.25 \pm 4.64)$ \\
\hline Highest educational level & $9(42.9 \%)$ \\
Primary educational level & $7(33.3 \%)$ \\
Ordinary level & $5(23.8 \%)$ \\
Advance level & \\
Disease stage & \\
\hline I & $2(9.5 \%)$ \\
II & $7(33.3 \%)$ \\
III & $9(42.8 \%)$ \\
\hline IV & $3(14.3 \%)$ \\
\hline
\end{tabular}

\section{Procedure}

Human Subjects approval was obtained from the Ethics Committee of School of Nursing of Yangzhou University prior to study initiation, with the IR code: YZUHL2021006. Parents received a recruitment letter informing them about the study and were asked to contact the Principle Investigator (PI) within one week if they were willing to participate in the study. Interested mothers signed and returned the consent form to the $\mathrm{Pl}$, after which the PI scheduled a face-to-face interview. Interviews were conducted by two researchers in a private room in the hospital. The semi-structured interview consisted of open-ended question, and determined after selecting 2 patients for pre-interview and discussion in our group (Table 2). Interviews were audio-recorded with permission, and lasted 25 to 72 min (median 45 min). The recordings were transcribed by a professional transcriptionist and verified for accuracy by the PI. 
Table 2

Interview questions

1. How do you interact with your daughter(s)? Can you describe the details of your relationship?

2. What is the impact of breast cancer diagnosis on your interaction with your daughter?

3. Could you tell me about your inner activities when interacting with your daughter after the diagnosis?

4. What impressed you during your interaction with your daughter after the diagnosis?

5. Is there anything you want to talk about that I didn't ask?

\section{Data Analysis}

Data of the interview were transcribed within 24 hours and in strict accordance with the requirements of the method of data system analysis, and return the sorted data to the research object to check the authenticity of the data. Two researchers independently read each transcribed text, extracted and encoded the statement. Then they classified those codes into themes and sub-themes and had regular and continuing discussion to verify the appropriateness of the conceptual meanings and terminology. And we employed the Colaizzi's phenomenological analysis method, which can provides a clear structure for data analysis.[21, 22] After interviews the researcher returns the fundamental structure statement to all participants to ask whether it captures their experience.[23] In addition, analytic frameworks and ideas from Foucauldian scholars are also partially integrated into the analysis for this research.[24] It examines deep meanings through making sense of the emergence of the smallest of statements.

\section{Result}

\section{Theme 1 Mothers are lost in chaos}

\section{Unable to deal with the shock of cancer}

This is the beginning of a new trajectory for the family when the diagnosis is conveyed. At that moment, mothers were under the information bombardment and felt blindsided by the huge amount of information they received about the diagnosis and the treatment options. It is difficult to deal with the shock of breast cancer for mothers who have never had contact with breast cancer. Therefore, mothers tend to choose to deal with devastating crises (such as diagnosis/treatment and marital crisis) under the shock of cancer and overlook the relationship of mother and daughter. Some mothers disclosed that their adolescent daughters were acutely aware of changes in the family atmosphere when they were not ready, this leaves mothers feeling unprepared.

P2 At that time, I didn't know how serious my illness was, I felt unsure about how to approach the issue. I'm confused! I was busy with my treatment and financial problems, which limited my communication with my daughter. 
P14 Of course, for a while after my diagnosis I was depressed about breast cancer. To tell you the truth, I don't know how clear I am about the results and don't have the energy to think about my relationship with my daughter.

\section{Powerlessness of the uncertainty about the life span}

The diagnosis of breast cancer is a great blow for mothers, they often associate cancer with death. Most mothers spoke about their likely limited life expectancy, and even if the newer treatments could extend her life, it would never be enough time. Mother plays a unique role in her daughter's life. They hope to give their daughter some life advice on her daughter's life path and stop their daughters when their daughters may enter the wrong crowed. But breast cancer has hindered mother's original role, they can't interact fully with their daughter at a limited time. Most of the mothers interviewed expressed their concerns and powerless about mortality, recurrence, and not seeing children grow up. The interaction between mother and daughter is hindered by mother's uncertainty about the future (sense of time) and their worry for their daughter's future.

P6 I'm confused about the future. I'm still adjusting myself. I don't know how long I can stay with my daughter and how to face her. Maybe I still need time to tidy up myself.

P19 The thing I think that makes me most upset is her (my daughter). I could talk about me and be like, "Yeah, it's me. I'm going to die one day." But it's her (my daughter) that makes me the most upset, I think.

P1 I just have this fear that ... if something happens in the next couple years.

\section{Confused about how to respond to daughter's curiosity}

Mothers have a trusting relationship with their daughters due to gender homogeneity. Evidence has shown that mothers are the preferred source of sexual knowledge and discussion for adolescent girls worldwide. However, because of the specificity of breast cancer, mothers with breast cancer should not only protect her daughter from the impact of her cancer, but also protect her daughter from the impact of mother's crippled breast. It is worth noting that adolescent girls are always curious about their physical changes,but most mothers are uncertainty about how to talk with their children about sexual issues (which is taboo in some cultures), and they to tend to limit the discussion to safe topics. And give to the role that mothers play in implicitly influencing daughters' views on secondary sexual characteristics (breasts), it is likely that more explicit communication about breast cancer could also impact aspects of adolescent daughters' body image. Many mothers hope to communicate their physical condition and treatment with their daughters, but they feel unsure about how to talk to their child and how much information to share with them, which makes them confused and tangled. The practical and emotional challenges of communicating with daughter complicate their mother-daughter interactions, they were aware they lacked a scarcity of evidence-based guideline to manage, but often were unsure how to do so.

P2 I feel puzzled. Actually, I want to communicate with her (about breast cancer), but I don't know how to do. My daughter is in puberty and secretly told me that her breasts are changing. She was full of curiosity 
about breasts and told me that her classmates had put on a vest. I dare not let her see my breast because I had a mastectomy. I'm afraid it will cause psychological shadow to her. I'm walking on eggshells!

P14 I think I should tell my daughter about my illness, but I'm struggling with what method to tell her. I didn't get any professional help in communicating with my daughter, nor did I find any information. I hope to get guidance on how to communicate and make it easier for children to accept the facts. This requires children's cooperation, and mainly depends on adults to guide. This part is still lacking, and no one gives me relevant guidance.

\section{Theme 2 Mothers struggle for balance \\ Protect daughter or let her be independent}

The influence of breast cancer makes these mothers to change the way of interaction with their daughters. They struggle between their daughter's independence or protection, trying to maintain a balance. After suffering from breast cancer, the mother struggled to hide or tell her daughter the truth of the disease. On the one hand, they are worried that their daughters will have a psychological burden when they know it. On the other hand, they feel they can't hide it and worried that their children will become more anxious when they don't know the truth. And factual explanation can promote daughters to become independent and get emotional support from their daughter, which is a way to mutually share strength. Most mothers $(n=18)$ with breast cancer say that she will tell her daughter when she can't hide, or at some point, observe her daughter's reaction and decide whether to tell her daughter about her condition.

Therefore, mothers tend to pay more careful attention to their daughter's behavior and language, but it is not without difficulty for mothers with breast cancer.

P8 I was afraid that telling her my illness would make her have a psychological burden, so I didn't tell her at first, but later I found that she was more worried. She guessed every day and was very upset. Then I decided to tell her that I chose to tell her when her school (enrollment and school selection) had been set.

P13 I didn't let my daughter go to the hospital before the treatment plan was decided. I don't want to cause psychological shadow to her. But my hair will fall off after chemotherapy. I can't hide it. I had to tell my daughter about my condition.

P20 I think it's better to show your down sides instead of trying to be strong all the time. I'll need my daughter's help, and I can make it with the courage she gives me. But I think she is still young. First, she doesn't know what cancer is. Second, tell her my condition may make her lose happiness, which is not what I want to see. I did not want to say too much to "scare them off", yet wanted to give their daughters knowledge to make them independent, and I'm looking for a chance to let her understand my condition.

\section{As a mother or a patient}

For those mothers whose daughters are minors, being a mother is a hard activity, such as volunteering at their daughter's school, going on field trips, driving children to and from daughters' school, and being 
present in daily life. Many participants $(n=16)$ expressed the importance of doing everything that they had previously done. But for mothers with breast cancer this was not always easy and required some modifications to daily life. As some mothers described, even if they suffer from cancer, even if they suffer from treatment pain, they still insist on doing housework and maintaining their children's daily life when their physical strength allows, hoping to minimize the impact on their daughters' study and life and reduce the burden on others. However, this was not always easy, they've got to rest all day to recover from doing so much other stuff or have to overdraft their physical strength. Therefore, in the process of illness, the mother must make some efforts to adjust and balance the relationship between mother and patient, to help daughters recognize their mother won't be able to do this and that for a while. Even though this is full of challenges, it is conducive to the development of mother's physical condition in a good direction.

P8 My daughter still asked me to send her to school and help her carry heavy things like I did when I was not ill, but sometimes my body can't bear it. Maybe my daughter will be more considerate to me when she realizes my condition and won't make unreasonable demands on me. I was thinking about whether to show my daughter my wound, which might hit her, but let her know a little about my condition, maybe I wouldn't be so tired.

P 12 I think if I were on my own, if I were a single person without kids, this would be easier for me to deal with because the most difficult part is dealing with the kids. I still insist on housework and taking care of the children's daily life even if I am ill, I want to give her the impression that I am still mom.

\section{Theme 3 Mothers are immersed in guilt Increasing risk of cancer for daughters}

Daughters can share the mother's genetic variations and, as such, disease risk. The presence of a hereditary cancer predisposition can make mothers feel guilty. And mothers felt exacerbate guilty when the daughter expressed blame to her mother for having passed along her increased risk. It's result in dysfunctional mother-daughter interactions. Though mothers understood that their risk or disease was not their fault and not within their control, they felt responsible for their daughter's disease risk. The guilt as an emotional, it's a challenge for breast cancer mother to use intellectual to overcome guilt to loosen mother daughter interaction.

P16 I'm very worried that my daughter will get breast cancer. Because my breast cancer can cause my daughter to have a higher rate of disease than others. Sometimes, when I see my daughter, I feel guilty for her because I think her future trajectory will have some bad changes because of my breast cancer.

P4 I'm very afraid that this disease will be passed on to my daughter. I'm very anxious.

\section{Influencing the development of daughter}

Mothers play a special and important role in a family and their breast cancer affects the development of the whole family, especially their daughters. They feel sadness, guilty and worry because they can't 
perform their responsibilities of raising children well, and they often think they have become a "bad mother". The adverse reactions of postoperative and radiotherapy have seriously affected the image of breast cancer patients, which may also lead to psychological problems such as low self-esteem and selfdoubt in the daughter of the patient. The experience of losing their mother will also affect adolescent daughters' emotions and personality. In addition, as adolescent daughters are in an important stage of learning, mothers are very worried that their diseases will put pressure on their children and affect their learning. For mothers was hitting by breast cancer, dealing with these intertwined emotions is a huge challenge.

P6 I used to take her swimming, but I can't take her anymore. Once my daughter came back and told me that when her classmates saw me her classmates all looked at us with strange eyes, and some even covered their mouths and smiled. I'm worried that my illness will affect my daughter's psychology and she will feel inferior. I don't think I'm a good mother.

P14 My daughter's grades are always ahead in the class, but I didn't help her with her homework after I was ill, so the teacher will find mistakes when checking her homework. Her teacher will criticize her and she will be unhappy when she comes home. I feel sad about it...

\section{Bring burden to daughter}

Mothers believe that breast cancer as a family genetic disease will affect their daughter's marriage, and their daughter's future partner will be estranged from her because she carries breast cancer genes. Some adolescent daughters even express that I'm never getting married and I know I'm gonna get cancer. In addition, their daughters, who are at high risk for breast cancer, need to pay attention to diet and physical examination, which may impose additional burden on their daughter's daily life. The enormous financial burden to families is also an important reason why mothers with breast cancer feel guilty. They feel that their illness has reduced the quality of life of the entire family, including their daughter. The mothers felt guilty about the burden they had placed on their daughter increase the difficulty of getting along with her daughter.

P21 My daughter kind of holds me responsible both for her cancer and marriage. I'm very worried... my breast cancer is bad for my daughter to get married. Her partner may be estranged from her.

P12 Our savings had to be used for treatment and bear the education and living expenses of our two children. Now I spend most of my money on cancer treatment, there will be no way to guarantee the future quality of life of my children.

\section{Discussion}

Previous research has demonstrated adolescence is a crucial phase for daughters to identify with their mothers, they move to independence in their own lives. Adolescent daughters experienced more emotional distress than sons, they are influenced by their mothers at a high level and shared changes on many levels.[25] However, few studies have explored the nuances of challenges in the interactions 
between breast cancer mothers and their adolescent daughters. This body of work reveals the experience of breast cancer mothers walking on eggshells in interacting with adolescent daughters and enhance health practitioners' understanding of mother-daughter dynamics and offer some guidance.

Lundquist et al. found that the hardest part of being a young woman with breast cancer is being a mother.[26] There are many conflicts between adolescent daughters and their mothers, and breast cancer brings extra pressure to the relationship between mothers and daughters.[27] As the mothers in our study disclosed, they are walking on eggshells, the uncertainty of information and relationship leads to difficulties in getting along with their daughters. They need to solve their inner confusion before they can solve the problem of interaction with their daughter but that is made particularly difficult given the physical and psychological problems related to breast cancer (e.g., lymphedema or depression).[28] Patients are in the information bombing during the period when they just learned that they had breast cancer. They can't consider what extent cancer will eventually destroy their bodies, and how much their future life will be affected by breast cancer. As some research results show, most mothers will choose to avoid getting along with their daughter in the early stage of the disease.[29] Until they solve their inner doubts or can't hide, they will talk with their daughters about clearly observable consequences (e.g., hospitalization, exhaustion/fatigue, and hair loss). During this period, they will be careful to get along with their daughters, which will hinder the development of mother daughter relationship and bring challenges to mothers suffering from breast cancer. Although avoidance is very understandable and helps reduce or prevent distress in the short run, in the long run, it often leading to even greater distress(e.g., decreased quality of life, elevated distress and anxious).[30, 31] In fact, mothers should adjust their attitudes towards diseases, actively understand the relevant information of breast cancer, and incorporate both direct communicative approaches (e.g., being honest and open or asking questions) and more indirect strategies (e.g., using humor, sugarcoating, or finding common ground) to communicate with adolescent daughters.

Adolescent daughters of breast cancer mothers are in a phase of life in which identity development is key to their health and facing the change of secondary sexual characteristics. [7] Their growth and struggles with their sense of self will involve their mother's cancer experience and their own disease risk because mothers are in a unique position to provide emotional validation, health education and secondary sexual characteristics guidance.[13] And as the mothers in our sample disclosed, mothers with breast cancer are more difficult to solve their daughter's physical problems during puberty than ordinary mothers, it's may attribute to breast cancer destroys the integrity of their body and possibly even putting their daughters at high risk for cancer. The experiences of health and disease are familial concerns rather than solely individual experiences.[32] It is important for health practitioners to pay attention to strategies and health promotion strategies between mothers with breast cancer and their adolescent daughters. Multimedia strategies tailored information about what to expect or do to be conveyed in a nonthreatening manner. Health practitioners can develop and use brochures, Web sites, and videos or interactive DVDs for breast cancer mothers and their adolescent daughters to help them navigate these conversations while simultaneously learning about health promotion together. In addition, group-oriented activities led by health practitioners could provide another platform for mothers and daughters to interact about breast 
cancer issues and boost mothers maintain balance between mother and daughter. And health practitioners could help daughters of elevated-/high-risk or diagnosed mothers form some sort of group to help adolescent daughters share a mother's risk or diagnosis with her peers and have a large enough support network.

Consistent with Tavares 's research,[32] we found that as a mother, they are under tremendous pressure and feel guilty after suffering from breast cancer. They afraid that their diseases and treatment will have a badly impact on the life, learning and psychology of their adolescent daughter. And even worry about the impact of their diseases on their daughter's future economy and marriage. Mothers can help mitigate this outcome by incorporating a life outside of cancer into mother-daughter relationship.[33] Furthermore, focusing on what they can do to improve their health and quality of life may help some mother face their daughters more relaxed. And discussions between health practitioners and breast cancer mothers should usually include a dialogue about multiple causes of breast cancer to eliminate some women's tendency to blame themselves for the only reason. Asking the mothers what they think is responsible for having developed cancer can open an important dialog about guilt and self-forgiveness, which may be helpful. [34]

\section{Limitations}

Findings from this study are limited by the fact that this sample of women is small and limited to the mothers' perspectives. In future studies, we can understand the psychological status, family function, communication and other related factors of breast cancer patients and their adolescent daughters through quantitative research, and explore the intervention measures for breast cancer mothers who are raising their minor children. In addition, future research should also capture the voices of the daughters to enhance interaction between mother and daughter.

\section{Conclusion}

Our findings explore the interaction experience of breast cancer mothers and daughters, and further reveal the nuances of mother-daughter interaction challenges faced by mother with breast cancer from mother' perspective. Challenges in the interactions between the mother and daughter faced by mothers with breast cancer are that mothers are lost in chaos, struggle to balance and immerse in guilt. We hope that these findings will help to presented ways in which mothers can enhance interaction with their daughters and learn to cope with cancer risk in a healthier manner. And assist health practitioners to translate our findings into health interventions.

\section{Declarations}

\section{Ethics approval and consent to participate}

This study was performed in line with the principles of the Declaration of Helsinki. Approval was granted by the Ethics Committee of School of Nursing of Yangzhou University, with the IR code: YZUHL2021006. 
At the beginning of the interview, we explained the target of the research to the participants and informed them that the interviews would be recorded but at any time they prefer the audio recording would be cut off. Informed consent was obtained from all participants and for participants below age 16 from their guardians before the interview, including for use of anonymous quotes.

\section{Consent for publication}

This manuscript does not report personal data such as individual details images or videos. Therefore, consent for publication is not applicable.

\section{Competing interests}

The authors declare that there is no conflict of interest. The material submitted is original and has not been submitted elsewhere.

\section{Funding}

This study was funded by the National Natural Science Foundation of China (82174129), the Postgraduate Research \& Practice Innovation Program of Jiangsu Province (No.KYCX20_3006), Science Foundation of Nursing Research of Yangzhou University (HX2002) and Young Backbone Teacher Foundation of Yangzhou University.

\section{Authors' contributions}

Concept-QYJ; design-PTZ, QYJ, XYL; interview-QYJ, XYL; data analysis-PTZ,QYJ,XYL,TX,QWW,YJW; data interpretation-PTZ,QYJ,XYL,TX,QWW,YJW; first draft-QYJ; revisions and final manuscriptPTZ,QYJ,XYL,TX,QWW,YJW.

\section{Acknowledgements}

The authors thank all the participants for their support and the staff of the Medical Officer of Health for their cooperation.

\section{Availability of Data and Materials}

The datasets used and analyzed in the current study are available from the corresponding author upon reasonable request.

\section{References}

1. Sung H, Ferlay J, Siegel RL, Laversanne M, Soerjomataram I, Jemal A, Bray F: Global cancer statistics 2020: GLOBOCAN estimates of incidence and mortality worldwide for 36 cancers in 185 countries. CA: a cancer journal for clinicians 2021.

2. Ferlay JEM LF, Colombet M, : Global Cancer Observatory:Cancer Today. 2021-05-29. 
3. Tavares R, Brandão T, Matos PM: Mothers with breast cancer: A mixed-method systematic review on the impact on the parent-child relationship. Psycho-oncology 2018, 27(2):367-375.

4. Huang X, Lee S, Hu Y, Gao H, O'Connor M: Chinese Children's Experience When the Mother Has Breast Cancer: Voices From Mothers and Children. Cancer nursing 2020, 43(2):158-166.

5. Wikle JS, Hoagland A: Adolescent interactions with family and emotions during interactions: Variation by family structure. Journal of family psychology: JFP : journal of the Division of Family Psychology of the American Psychological Association (Division 43) 2020, 34(5):544-554.

6. Wellisch DK, Gritz ER, Schain W, Wang HJ, Siau J: Psychological functioning of daughters of breast cancer patients. Part I: Daughters and comparison subjects. Psychosomatics 1991, 32(3):324-336.

7. Borysenko J: A woman's book of life: The biology, psychology, and spirituality of the feminine life cycle. New York: Riverhead Books; 1996.

8. Coughlin SS: Epidemiology of Breast Cancer in Women. Advances in experimental medicine and biology 2019, 1152:9-29.

9. Chan A, Lomma C, Chih H, Arto C, McDonald F, Patterson P, Willsher P, Reid C: Psychosocial consequences in offspring of women with breast cancer. Psycho-oncology 2020, 29(3):517-524.

10. Steensma TD, Kreukels BP, de Vries AL, Cohen-Kettenis PT: Gender identity development in adolescence. Hormones and behavior 2013, 64(2):288-297.

11. De Silva NK: Breast development and disorders in the adolescent female. Best practice \& research Clinical obstetrics \& gynaecology 2018, 48:40-50.

12. Hart E, Chow CM: "I just don't want to be fat!": body talk, body dissatisfaction, and eating disorder symptoms in mother-adolescent girl dyads. Eating and weight disorders: EWD 2020, 25(5):12351242.

13. Maloney E, Edgerson S, Robson M, Offit K, Brown R, Bylund C, Kissane DW: What women with breast cancer discuss with clinicians about risk for their adolescent daughters. Journal of psychosocial oncology 2012, 30(4):484-502.

14. Dalton L, Rapa E, Ziebland S, Rochat T, Kelly B, Hanington L, Bland R, Yousafzai A, Stein A: Communication with children and adolescents about the diagnosis of a life-threatening condition in their parent. Lancet (London, England) 2019, 393(10176):1164-1176.

15. Inbar C, Ety B, Ayala H, Tamer P: The mental health of breast cancer survivors and their adolescent daughters. Psycho-oncology 2013, 22(6):1236-1241.

16. Bradbury AR, Patrick-Miller L, Schwartz L, Egleston B, Sands CB, Chung WK, Glendon G, McDonald JA, Moore C, Rauch P et al: Psychosocial Adjustment in School-age Girls With a Family History of Breast Cancer. Pediatrics 2015, 136(5):927-937.

17. Ali A, Fergus K, Wright FC, Pritchard KI, Kiss A, Warner E: The impact of a breast cancer diagnosis in young women on their relationship with their mothers. Breast (Edinburgh, Scotland) 2014, 23(1):5055 . 
18. Berlin KL, Andreotti C, Yull F, Grau AM, Compas BE: Mother-daughter communication about breast cancer risk: interpersonal and biological stress processes. Journal of behavioral medicine 2013, 36(3):328-339.

19. Foucault M: The history of sexuality: Vintage; 2012.

20. Botes A: Qualitative Research in Nursing: Advancing the Humanistic Imperative. Health $S A$ Gesondheid 1996, 1(1).

21. Colaizzi P: Psychological research as a phenomenologist views it. Existential Phenomenological Alternatives for Psychology 1978.

22. Edward KL, Welch T: The extension of Colaizzi's method of phenomenological enquiry. Contemporary nurse 2011, 39(2):163-171.

23. Morrow R, Rodriguez A, King N: Colaizzi's descriptive phenomenological method. 2015.

24. Forrester MA: Doing qualitative research in psychology: A practical guide: Sage; 2010.

25. Brown RT, Fuemmeler B, Anderson D, Jamieson S, Simonian S, Hall RK, Brescia F: Adjustment of children and their mothers with breast cancer. Journal of pediatric psychology 2007, 32(3):297-308.

26. Lundquist DM, Berry DL, Boltz M, DeSanto-Madeya SA, Grace PJ: I'm Still Mom: Young Mothers Living With Advanced Breast Cancer. Oncology nursing forum 2020, 47(4):405-414.

27. Stiffler D, Haase J, Hosei B, Barada B: Parenting experiences with adolescent daughters when mothers have breast cancer. Oncology nursing forum 2008, 35(1):113-120.

28. Kim S, Ko YH, Jun EY: The impact of breast cancer on mother-child relationships in Korea. Psychooncology 2012, 21(6):640-646.

29. Huang X, O'Connor M, Hu Y, Gao H, Lee S: Communication About Maternal Breast Cancer With Children: A Qualitative Study. Cancer nursing 2017, 40(6):445-453.

30. Figueiredo MI, Fries E, Ingram KM: The role of disclosure patterns and unsupportive social interactions in the well-being of breast cancer patients. Psycho-oncology 2004, 13(2):96-105.

31. Lee M, Song Y, Zhu L, Ma GX: Coping Strategies and Benefit-finding in the Relationship between Nondisclosure and Depressive Symptoms among Breast Cancer Survivors in China. American journal of health behavior 2017, 41(4):368-377.

32. Li Y, Wang K, Yin Y, Li Y, Li S: Relationships between family resilience, breast cancer survivors' individual resilience, and caregiver burden: A cross-sectional study. International journal of nursing studies 2018, 88:79-84.

33. Fisher CL, Maloney E, Glogowski E, Hurley K, Edgerson S, Lichtenthal WG, Kissane D, Bylund C: Talking about familial breast cancer risk: topics and strategies to enhance mother-daughter interactions. Qual Health Res 2014, 24(4):517-535.

34. Werner-Lin A, Merrill SL, Brandt AC, Barnett RE, Matloff ET: Talking with Children About Adult-Onset Hereditary Cancer Risk: A Developmental Approach for Parents. Journal of genetic counseling 2018, 27(3):533-548. 